\title{
Bacillus pumilus Marinos Inhibidores de la Fijación de Microalgas a Sustratos Artificiales
}

\author{
Yanett E. Leyton*, Arlette S. Letelier, María Teresa Mata y Carlos E. Riquelme \\ Centro de Bioinnovación de Antofagasta (CBIA), Facultad de Ciencias del Mar y Recursos Biológicos. \\ Universidad de Antofagasta, Angamos 601, Antofagasta- Chile (email: yanett.leyton@uantof.cl; \\ arlette.letelier@gmail.com; maytemcontreras@gmail.com; carlos.riquelme@uantof.cl)
}

${ }^{*}$ Autor a quien debe ser dirigida la correspondencia

Recibido Sep. 5, 2016; Aceptado Oct. 3, 2016; Versión final Nov. 11, 2016, Publicado Abr. 2017

\section{Resumen}

Se evalúa la inhibición de la fijación microalgal en sustratos artificiales, previamente colonizado con bacterias marinas. Debido a la escasez de agua, la región de Antofagasta en Chile desarrolla la desalinización del agua de mar para sus procesos mineros. La carga biológica del agua de mar genera bioincrustaciones que obstruyen los sistemas de flujo. Las bioincrustaciones se inician con la fijación inicial de moléculas y microorganismos como bacterias y microalgas, los cuales sirven de sustrato y alimento para otros colonizadores. Dos cepas de Bacillus pumilus inhibieron la adherencia de mezclas microalgales, demostrando que estarían secretando metabolitos inhibidores de la fijación. Por lo tanto se concluye que es viable utilizar bacterias marinas como B. pumilus para inhibir la fijación inicial a sustratos artificiales como PVC, de microalgas nativas de las costas del norte de Chile.

Palabras claves: bioincrustación; Bacillus pumilus; inhibición; microalga; desalinización

\section{Marine Bacillus pumilus Inhibitors of the Fixation of Microalgae to Artificial Substrates}

\begin{abstract}
The inhibition of microalgal fixation in artificial substrates, previously colonized with marine bacteria is evaluated. Due to the shortage of water, the region of Antofagasta in Chile develops desalination of seawater for its mining processes. The Bioburden of the seawater generates biofouling and obstructing of the flow systems. Biofouling start with the initial attachment of molecules and microorganisms like bacteria and microalgae, which serve as substrate and food for other colonists. Two strains of Bacillus pumilus inhibited adhesion of microalgal mix, showing that they produce metabolites that inhibits fixation. It is therefore concluded that it is feasible to use of the marine bacteria $B$. pumilus to inhibit the initial fixation to artificial substrates such as PVC, of native microalgae the coasts of northern Chile.
\end{abstract}

Keywords: biofouling; Bacillus pumilus; inhibition; microalgae; desalination 


\section{INTRODUCCIÓN}

Las bioincrustaciones (Biofouling en inglés) implica un proceso de sucesión natural en el que una superficie se incrusta de microorganismos y sus productos derivados (Qureshi et al., 2015). Estas bioincrustaciones comprenden desde proteínas, polisacáridos y proteoglicanos (Maitrayee, 2012), seguido por la colonización de microorganismos como bacterias (Flemming y Wingender, 2010). Luego por diatomeas que son las principales microalgas colonizadoras de sustratos contaminados (Yang et al., 2015). Finalmente colonizan los sustratos macro organismos como invertebrados marinos, generando posteriormente una acumulación estable que provocan graves problemas (Jhaveri y Murthy, 2016). Se atribuye el término de contaminación biológica cuando los microorganismos sobrepasan el umbral de interferencias y se convierten en "molestia" (Qureshi et al., 2015).

La problemática de biocorrosión y bioincrustaciones es común en plantas de tratamiento de agua que usan agua de mar debido a las sales o minerales que contiene y a la contaminación biológica de micro y macro organismos presentes en el agua. Beech et al., (2005) discuten que la biocorrosión generada por microorganismos y sus exopolisacaridos promueve reacciones fisicoquímicas que estimulan la posterior sucesión de macro organismos. Los principales problemas que generan las bioincrustaciones en las plantas de tratamiento de agua entre otras cosas son obstrucciones en tuberías, disminución de flujo de permeación o filtración, reducción de la vida útil de la membrana y alta demanda de energía para filtración (Jhaveri y Murthy, 2016). Al respecto, hay evidencia científica que comprueba la incidencia del sustrato en la fijación de macro organismos como Zhao y Qian, (2002) quienes comprobaron que el $99 \%$ del asentamiento de la lapa Credidula onix fue en respuesta a las señales de bioincrustaciones del sustrato. Igualmente, Khandeparker et al., (2003) encontraron que las bioincrustaciones de Pseudomonas aeruginosa indujeron hasta un $44 \%$ el asentamiento de larvas de Balanus amphitrite. Las bioincrustaciones generan problemáticas que se traducen en fuertes gastos financieros asociados a limpieza frecuente y sustitución de membranas lo que aumenta el costo operativo (Matin et al., 2011). Una medida de mitigación sería prevenir la contaminación biológica o bioincrustantes en las primeras etapas de formación, inhibiendo los primeros colonizadores bacterianos y microalgales. Así como igualmente lo sugieren Kochkodan y Sharma, (2012) quienes indican que la reducción de las interacciones no deseadas entre incrustantes y la superficie de la membrana puede ser un método para controlar la adherencia de suciedades. Al respecto, Khan et al., (2016) indican que los microorganismos prefieren vivir en comunidades auto organizadas tridimensionales (bioincrustaciones), este comportamiento proporciona diversos hábitat para patógenos microbianos. Así las bacterias que conforman estas bioincrustaciones potencian su resistencia permitiéndolas vivir en condiciones adversas (Rabin et al., 2015).

Los organismos han desarrollado durante tiempos geológicos a través de la selección natural, diferentes mecanismos como sistema de defensa y/o adaptación a los cambios del ecosistema. Existe evidencia que la naturaleza proporciona productos antibioincrustaciones secretados por microorganismos (Tan et al., 2010; Susilowati et al., 2015). Por ejemplo, Qian et al., (2015) reportaron 214 compuestos naturales marinos con propiedades antibioincrustaciones. Dobretsov et al., (2015) observaron que el coral Cladiella sp. tiene bacterias asociadas a sus estructuras que inhiben la fijación de otras bacterias como Cytophaga sp., Pseudomonas sp., Psychrobacter sp., Shewanella sp., relacionadas con contaminación biológica. Los autores sugieren que los corales han desarrollado estos mecanismos de protección para combatir las infecciones e inhibir las bioincrustaciones bacterianas. Por otro lado, Qi et al., (2009) observaron que dicetopiperazinas extraídos desde la bacteria Pseudomonas rhizospherae actúan como inhibidores de la adhesión del briozoo B. neritina y larvas de Balanus amphirite. Igualmente, los resultados de $\mathrm{Li}$ et al., (2006) demostraron que dicetopiperazinas extraída desde Streptomyces fungicidicus inhibió la fijación de $B$. amphirite.

Estos antecedentes demuestran que los organismos marinos son fuente prometedora de productos naturales. Aplicar productos activos bacterianos actualmente son una buena alternativa considerando que hay legislaciones internacionales que están prohibiendo el uso de biocidas antibioincrustaciones debido a su toxicidad para el medio ambiente (Almeida y Vasconcelos, 2015). Ante este escenario existe la necesidad de buscar nuevas estrategias ecológicas que permitan impedir la fijación a un sustrato de bacterias y microalgas formadoras de bioincrustaciones. El objetivo de este trabajo fue aislar e identificar bacterias marinas inhibidoras de las primeras etapas de formación de bioincrustaciones o del denominado "biofouling primario" el cual está constituido por microalgas.

\section{MATERIALES Y MÉTODOS}

Se describe la obtención de bacterias y microalgas, luego se explican los métodos para identificar bacterias y microalgas, se detalla la evaluación de actividad anti biopelículas en sustratos y se explica cómo se realiza el análisis de datos: 


\section{Obtención de bacterias y microalgas}

Las cepa M9-5-MESO fue recolectada desde biopelículas adheridas a rocas del intermareal de la Bahía San Jorge de Antofagasta, Chile (coordenadas: 2342'13.2"S, 70 25'29.8"W). Las rocas se rasparon con hisopo estéril, las que se depositaron en tubos de vidrio con medio TSB (Tryptone Soya Broth, Difco) suplementado con $2 \%$ de $\mathrm{NaCl}$ (Oxoid) y se trasladaron al Laboratorio Mesocosmos Marino de la Universidad de Antofagasta donde se incubaron por 48 horas a $20^{\circ} \mathrm{C}$. Luego se sembraron en extendido sobre placas con medio Agar Marino 2216 (Difco), se incubaron por 24 horas a $37^{\circ} \mathrm{C}$. Las colonias fueron aisladas en medio TSA (Tryptone Soya Agar, Difco) suplementado con $2 \%$ de $\mathrm{NaCl}$ (Oxoid) utilizando la técnica de sembrado en estrías. La bacteria Bacillus pumilus C32-MESO fue obtenida desde el cepario de colección del Laboratorio Mesocosmos Marino de la Universidad de Antofagasta la cual fue aislada previamente por Leyton y Riquelme, (2010). Como control positivo se usó la bacteria Alteromonas sp Ni1LEM obtenida desde el cepario de colección del Laboratorio de Ecología Microbiana de la Universidad de Antofagasta, la cual ha sido reportada y patentada su actividad antifouling (Riquelme et al., 2008). Las cepas bacterianas fueron guardadas en cepario, para lo cual, con un asa estéril se traspasó un inóculo de cada cepa a tubos Cryobank (Copan) para su conservación a $-20^{\circ} \mathrm{C}$. Además las cepas se mantuvieron en placas de TSA incubadas a $20^{\circ} \mathrm{C}$ para su utilización.

Las muestras de microalgas fueron recolectadas desde biopelículas adheridas a rocas del intermareal de la Bahía San Jorge de Antofagasta (Chile) (coordenadas: 23³6'57.2"S, 70²3'33.8"W y $\left.23^{\circ} 42^{\prime} 13.2^{\prime \prime} \mathrm{S}, 70^{\circ} 25^{\prime} 29.8^{\prime \prime} \mathrm{W}\right)$. Las rocas se rasparon con hisopo estéril y después se cultivaron en medio líquido F/2 (Guillard y Ryther, 1962), usando agua de mar filtrada (0,2 micras) y autoclavada como base. Luego fueron sembradas en placas de cultivo con el mismo medio F/2 más la adición de agar bacteriológico para aislar colonias unialgales. Una vez obtenido el cultivo monoalgal, se creció en medio líquido $\mathrm{F} / 2$ a $20^{\circ}$ $\mathrm{C}$, con una irradiación de $80 \mu \mathrm{mol}$ fotones $\mathrm{m}^{-2} \mathrm{~s}^{-1} \mathrm{y}$ un fotoperiodo de 12:12 h luz: oscuridad, para su mantenimiento en el cepario del laboratorio Mesoscosmos Marino.

\section{Métodos para identificar bacterias y microalgas}

Se tomaron 10 uL de inóculo en SSM (Solución Salina Marina) y se sembraron en tubos eppendorf con 1 $\mathrm{mL}$ de medio TSB. Luego de 24 horas a $37^{\circ} \mathrm{C}, 10 \mathrm{uL}$ fueron sembrados en extendido en placas de TSA donde se dejó crecer por 24 horas a $37^{\circ} \mathrm{C}$. Transcurrido este tiempo, el ADN de cada aislado fue extraído usando el kit MoBio PowerSoil $($ DNA Isolation (MoBio Laboratories), siguiendo las instrucciones del fabricante. Mediante la técnica de PCR (Polymerase Chain Reaction), el gen 16S ADNr fue amplificado utilizando los partidores 27F (5`-AGAGTTTGATCCTGGCTCAG-3') y $1542 R \quad$ (5`AGGAGGTGATCCAGCCGCA-3`) previamente descritos por Brosius et al., (1981).

La amplificación de los productos se realizó en un termociclador 2720 (Applie Biosystem) las condiciones de PCR fueron $5 \mathrm{~min}$ a $94^{\circ} \mathrm{C}$, luego 30 ciclos de $45 \mathrm{~s}$ a $94^{\circ} \mathrm{C}$ de desnaturalización, luego $45 \mathrm{~s}$ a $55^{\circ} \mathrm{C}$ de alineamiento, $90 \mathrm{~s}$ a $72^{\circ} \mathrm{C}$ de elongación, seguido por $5 \min$ a $72^{\circ} \mathrm{C}$ y finalmente un período de conservación a $4^{\circ} \mathrm{C}$. Para $30 \mathrm{uL}$ de volumen final de reacción se utilizaron $5 \mu \mathrm{g} / \mathrm{mL}$ de Buffer Green 10x, $2 \mu \mathrm{l} \mathrm{de} \mathrm{MgCl}_{2}$ a $25 \mathrm{mM}, 0.5 \mu \mathrm{l}$ de Dntp`s, $1 \mu \mathrm{l}$ de cada partidor $10 \mu \mathrm{M}, 19.25 \mu \mathrm{l}$ de agua libre de nucleasas, $0.25 \mu \mathrm{l}$ de Go

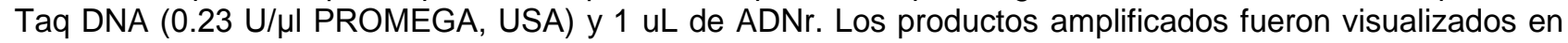
gel de agarosa $1 \%$, corrido por 45 min a 80 Volts.

EI ADN genómico de las microalgas fue extraído usando el kit PowerSoilß MoBio (MoBio Laboratories). Para la amplificación por PCR del 18S ribosomal se emplearon los primers 18S Forward (5'TGATGGTACCTACTACTCGGA-3') y 18S Reverse (5'- ACGGGCGGTGTGTACAAA-3') según Hsin-Pei et al., (2016). La amplificación por PCR se realizó con $100 \mathrm{ng}$ de ADN extraído en un volumen final de reacción de $30 \mu \mathrm{L}$. La reacción de PCR contenía $5 \mu \mathrm{L}$ de Green Buffer 10x, $0.5 \mu \mathrm{l}$ dNTPs a $10 \mathrm{mM}, 2 \mu \mathrm{l} 25 \mathrm{mM} \mathrm{MgCl}_{2}$, $1 \mu \mathrm{l}$ de cada primer a $10 \mathrm{mM}$ y $0.25 \mu \mathrm{l}$ GoTagADN polimerasa ( $0.23 \mathrm{U} / \mu \mathrm{I}$ PROMEGA, USA). El programa de PCR consistió en una desnaturalización inicial a $95^{\circ} \mathrm{C}$ durante 5 min y 35 ciclos incluyendo 30 segundos de desnaturalización a $94^{\circ} \mathrm{C}, 1$ min de alineamiento a $55^{\circ} \mathrm{C}$ y 1 min de elongación a $72^{\circ} \mathrm{C}$.

Por último, se realizó la elongación durante 5 min a $72^{\circ} \mathrm{C}$, seguido por almacenamiento a $4^{\circ} \mathrm{C}$. El producto de PCR se purificó con un kit de purificación (UltraCleanTM15 ADN, Mobio Laboratories, CA, EE.UU) según las instrucciones del fabricante. Los productos PCR fueron verificados en un gel de agarosa al $1 \%$ corrido por $45 \mathrm{~min}$ a 80 Volts. Los productos de PCR purificados de bacterias y microalgas fueron secuenciados por Macrogen Inc., Korea. Las secuencias obtenidas fueron analizadas, alineadas y limpiadas usando el programa Chromas Pro y la identificación se realizó empleando la herramienta de comparación de secuencias génicas Blast y la base de datos de GenBank (NCBI, 2016). 


\section{Evaluación de actividad anti bioincrustantes en sustratos}

Se evaluó la inhibición de la formación de biopelículas microalgales en sustratos previamente incrustados con bacterias. Para ello, tubos de PVC (Policloruro de vinilo) fueron cortados en trozos de $4 \mathrm{~cm}^{2}$, se lavaron y luego esterilizaron a $121^{\circ} \mathrm{C}$ por $15 \mathrm{~min}$. Los sustratos de PVC se incorporaron a botellas Schott con $500 \mathrm{ml}$ de medio M9 según Gerhardt (1994) y para su bio incrustación con bacterias se inoculó por separado a una concentración de $1 \times 10^{6}$ cél $/ \mathrm{ml}$ de las cepas Ni1 (Control positivo) y C32 (cepario de colección), la cepa M9-5 (aislada del intermareal) y una mezcla de las 3 bacterias. El control negativo, fue sustratos de PVC sin bacterias los que recibieron el mismo tratamiento de incubación que los sustratos incrustados con bacterias. Todo el sistema (tratamientos y controles) se incubó a $30^{\circ} \mathrm{C}$ por 72 horas, luego de este tiempo de bioincrustación, se eliminó el medio de cultivo de cada botella y los sustratos fueron lavados 2 veces con agua de mar estéril para eliminar las bacterias que no se fijaron al sustrato. Luego fueron depositados en bolones estériles de $1 \mathrm{~L}$ conteniendo $600 \mathrm{ml}$ de agua de mar filtrada a 0,2 $\mathrm{mm}$. Cada sustrato se colgó con nylon de $0.35 \mathrm{~mm}$ previamente autoclavado, de manera que quedaran sumergidos en el agua. Se usaron 2 mezclas (Mix) microalgales para evaluar su fijación sobre sustratos bioincrustados previamente con bacterias: Mix UA (AC1-MESO, AC2-MESO, AC3-MESO y AC4-MESO) y Mix C14/C16 (AC14-MESO y AC16-MESO). Cada tratamiento se realizó por triplicado. Las microalgas en todos los tratamientos y control se inocularon a una concentración final de $1 \times 10^{4} \mathrm{cél} / \mathrm{ml}$.

Finalmente la experiencia se incubó a $20^{\circ} \mathrm{C}$ con agitación, aireación y fotoperiodo continuo. La medición se realizó a las 96 horas de incubación. En condiciones estériles se tomaron 2 sustratos de cada bolón, fueron lavados con SSM e introducidos en tubos Corning de $50 \mathrm{ml}$ con $10 \mathrm{ml}$ del SSM con solución de I2/KI al $5 \%$ de concentración final. Las células microalgales fueron separadas de los sustratos con un sonicador de vástago Sonics Vibra Cell por $20 \mathrm{~s}$ a $6 \mathrm{kHz}$. Los tubos fueron concentrados en una centrífug a Sigma 2-16KL a $5000 \mathrm{rpm}$ por $10 \mathrm{~min}$, se eliminó el sobrenadante obteniendo un volumen final de $200 \mathrm{uL}$. Los tubos fueron sonicados a baño maría por $10 \mathrm{~min}$ a $15.9 \mathrm{kHz}$ en un baño sonicador HILAB y homogeneizados brevemente. La concentración microalgal fue calculada por recuento en cámara de Neubauer en un microscopio Olimpus IX71.

\section{Análisis de datos}

Los datos fueron graficados y procesados estadísticamente con el programa Statgraphics Centurion XVI.I, se evaluó prueba de hipótesis con $95 \%$ de confiabilidad, análisis de varianza ANOVA y prueba de confiabilidad LSD (Least Significant Differences).

\section{RESULTADOS Y DISCUSIÓN}

Los resultados se presentan y discuten en dos subsecciones: (i) identificación de aislados bacterianos y microalgales y (ii) inhibición de biopelículas microalgales.

\section{Identificación de aislados bacterianos y microalgales}

Desde sustratos rocosos del intermareal de la Bahía San Jorge de Antofagasta se aisló la cepa M9-5MESO, las técnicas de secuenciación del gen $16 \mathrm{~S}$ ribosomal permitieron identificarla como Bacillus pumilus. El número de acceso de la cepa con mayor similitud al compararla en la base de datos de Genbank fue NR_112637.3 con un $100 \%$ de similitud y 0.0 de E-value. B. pumilus es una bacteria Gram positiva, aeróbica, con forma de bastón, formadora de esporas y frecuentemente son encontradas en suelo y medioambientes marinos donde componen la mayor cantidad de comunidades bacterianas marinas (Ortigosa et al., 1997). Debido a su capacidad de formar esporas y resistir un rango variable de condiciones medioambientales, se puede adaptar fácilmente a distintos hábitats (Priest, 1993) y sobrevivir en condiciones adversas, como por ejemplo, baja o nula disponibilidad de nutrientes, desecación, irradiación, $\mathrm{H}_{2} \mathrm{O}_{2}$ y desinfectantes químicos (Nicholson et al., 2000).

El borde costero en la región de Antofagasta está expuesto constantemente a contaminantes generados por los procesos mineros, dado al gran desarrollo de esta actividad. Estas condiciones inciden en el metabolismo de la diversidad microbiana que utilizan los metales pesados presentes en su hábitat. Zhipeng et al., (2016) indican que la distribución de la comunidad fitoplanctónica está influenciada por la temperatura de las diferentes estaciones del año, nutrientes como fosfato, metales pesados como cobre, cadmio y plomo. La Bahía San Jorge Antofagasta, está expuesta a diferentes metales por la cercanía de industrias mineras, cuya diversidad microalgal permitió aislar e identificar del intermareal diferentes especies las que fueron agrupadas en 2 Mix nombrados como: Mix UA (Prestauroneis integra., Achnanthes sp., Thalassiosira sp. y Bacillariophyta spp.) y el Mix AC14/AC16 (Pasammodictyon sp. y Tetraselmis marina) (Tabla 1). En otros trabajos, Bacillariophyta fue identificado como una de las familias 
de diatomeas más abundantes en las biopelículas fijadas en estanques de cultivo de pepinos de mar Apostichopus japonicus (Liming et al., 2016). Otros autores como Zhang et al., (2016) igualmente identificaron la abundancia en un $60 \%$ de especies pertenecientes a la familia de Bacillariophyta en la Bahía Bohai, China. Igualmente Zhipeng et al., (2016) demostraron que Bacillariophyta representó la mayoría de las especies (86.2\%) en la isla Xiaoheishan, China.

Tabla 1: Microalgas aisladas e identificadas desde el Intermareal de la Bahía San Jorge de Antofagasta, formadoras de bioincrustrantes.

\begin{tabular}{|c|c|c|c|c|c|}
\hline Mix & Cepa & Especie & $N^{\circ}$ acceso & E value & $\%$ Similitud \\
\hline \multirow{4}{*}{ UA } & AC1-MESO & Prestauroneis integra & gb|AM502025.1| & 0.0 & $99 \%$ \\
\cline { 2 - 6 } & AC2-MESO & Achnanthes sp. & gb|KM507855.1| & $8 \mathrm{e}-173$ & $98 \%$ \\
\cline { 2 - 6 } & AC3-MESO & Thalassiosira sp. & gb|AJ535171.1| & 0.0 & $100 \%$ \\
\cline { 2 - 6 } & AC4-MESO & Bacillariophyta spp. & gb|KF177758.1| & 0.0 & $99 \%$ \\
\hline \multirow{3}{*}{ AC14/AC16 } & AC14-MESO & Psammodictyon sp. & gb|JQ885984.1| & 0.0 & $99 \%$ \\
\cline { 2 - 6 } & AC16-MESO & Tetraselmis marina & gb|HE610131.1| & 0.0 & $99 \%$ \\
\hline
\end{tabular}

El género Prestauroneis el año 2006 fue integrado a la familia Stauroneidaceae (Bruder, 2006). Posteriormente, se integró al género la especie Navicula integra (Levkov y Williams, 2011), a pesar de esta modificación se sigue encontrando publicaciones de esta especie con el nombre antiguo. Como en el caso de Majewska et al., (2012) quienes aislaron a $N$. integra desde sustratos en la desembocadura del rio estuarino Vistula en Polonia, expuesto durante 100 años a influencias naturales y humanas. Igualmente, Ivorra et al., (1999) aisló $N$. integra desde un río contaminado por una fábrica de Zinc en la frontera belgaholandesa. En ambos estudios las microalgas se han aislado desde sustratos alterados, ya sea, por influencia natural o humana. Según Round et al., (1990) Psammodictyon es un género marino que vive en superficies de sedimentos arenosos. Al-Aarajy, (2001) aislaron P. panduriformis desde peces muertos del noroeste del Golfo Arábico. Igualmente P. panduriformis var. minor se ha aislado desde aguas superficiales de la Antártida (Cefarelli et al., 2016). Especies como Achnanthes sp., se aislaron desde biopelículas del caparazón de tortugas marinas (Robinson et al., 2016). Por otro lado, estudios de Suresh et al., (2016) discuten que Achnanthes sp., es una microalga que induce el asentamiento de macroorganismos, al observar que su presencia en sustrato indujo el asentamiento del poliqueto Hydroides elegans. Diatomeas como Achnanthes sp y Thalassiosira sp., fueron aisladas de muestras de la columna de agua del estrecho de Singapur (Tan et al., 2016). Igualmente, Thalassiosira sp., fue aislada desde sustrato sumergidos en la Bahía de Val en Croacia (Mejdandžić et al., 2015). Finalmente, la microalga Tetraselmis marina aislada en este trabajo a diferencia de las otras microalgas no se ha reportado como formadora de biopelículas. Un estudio interesante encontrado de esta especie se refiere a su capacidad de desintoxicar xenobióticos tales como diclorofenoles, usados ampliamente en la producción de plaguicidas, herbicidas que son una gran problemática del medio ambiente (Petroutsos et al., 2008).

\section{Inhibición de bioincrustaciones microalgales}

En la experiencia Mix UA se observó que las microalgas adheridas a sustratos previamente incrustados con bacterias fue menor respecto a los tratamientos sin bacterias, con diferencias significativas $(p \leq 0.05)$ y un porcentaje de confiabilidad de $95 \%$. Los valores obtenidos en $\mathrm{cél} / \mathrm{cm}^{2}$ fueron: El Control sin bacterias fijadas fue de 2979, respecto a los tratamientos con bacterias en Ni1 (control positivo) de 292, M9-5 con 417, C32 con 1313 y Mix bacteria 229 (Figura 1). Respecto al Mix AC14/AC16 igualmente se observó que las microalgas adheridas a sustratos previamente incrustados con bacterias fue menor respecto a los tratamientos sin bacterias, con diferencias significativas $(p \leq 0.05)$ y un porcentaje de confiabilidad de $95 \%$. Los valores obtenidos en cél/ $\mathrm{cm}^{2}$ fueron: Control de 2646, respecto a los tratamientos Ni1 (control positivo) 63, M9-5 con 500, C32 con 854 y Mix bacteria 1542 (Figura 2). En ambas experiencias la concentración del "control negativo" fue $0\left(\right.$ cél/ $\left.\mathrm{cm}^{2}\right)$ por lo que este dato no fue graficado.

Los resultados obtenidos en ambas experiencias comprueban la adherencia a los sustratos de las microalgas a las 96 horas. Y basándonos en estos resultados podemos inferir que hubo fijación de bacterias en los sustratos a las 72 horas de fijación. Confirmando los resultados de Mejdandžić et al., (2015) quienes afirman que cada sustrato que se sumerge al agua de mar se cubre rápidamente de una inevitable biopelícula bacteriana, seguida por cianobacterias y diatomeas. Nuestros resultados demostraron que la adherencia al sustrato de bacterias específicas puede generar inhibición o una fijación más tardía de microalgas al sustrato. Al respecto estudios de interacciones bacterias-microalgas han evidenciado un efecto significativo de las relaciones mutualistas o parasitarias de las bacterias en el crecimiento de microalgas. Se ha demostrado que hay bacterias promotoras del crecimiento microalgal y que viven en 
simbiosis con las microalgas, como por ejemplo producen ácido indol-3-acético y vitamina B12 que promueven el crecimiento microalgal. Además, mejora los niveles intracelulares de carbohidratos, lípidos y pigmentos de las microalgas (Fuentes et al., 2016). Futuras investigaciones deben hacerse para aclarar si el efecto inhibidor de las bacterias anti bioincrustantes como las encontradas en este trabajo, es sólo sobre la microalga o sobre el consorcio simbiótico afectando a las bacterias asociadas a las microalgas e indirectamente inhibiendo el crecimiento microalgal.

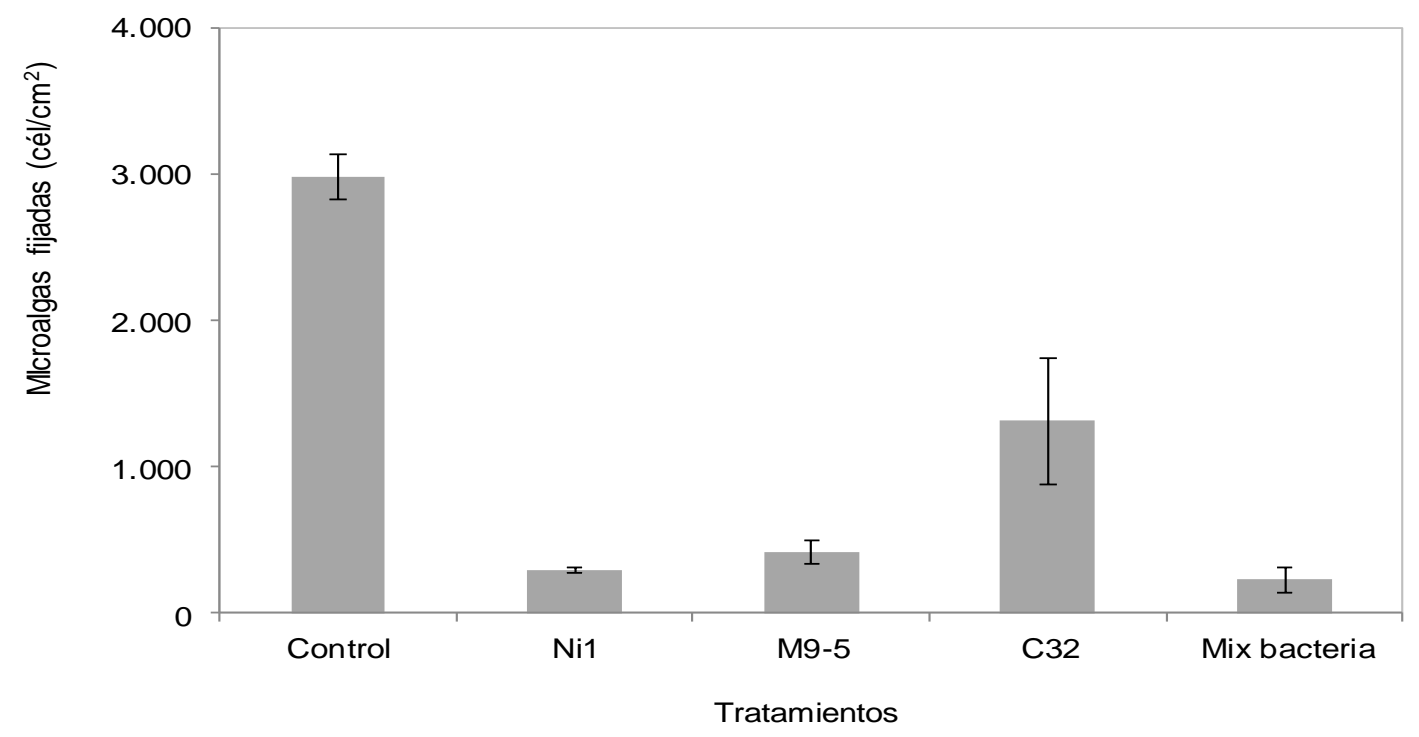

Fig. 1: Adherencia del Mix UA a sustratos bioincrustados con bacterias. Control: Mix UA; Ni1: bacteria Ni1-LEM+Mix UA; M9-5: bacteria M9-5-MESO+Mix UA; C32: bacteria C32MESO+Mix UA; Mix bacteria: bacteria Ni1-LEM+M9-5-MESO+C32-MESO+Mix UA.

Es interesante considerar la posibilidad de aplicar anti bioincrustantes de metabolitos microbianos, como una medida natural compatible con el medio ambiente. Sin embargo, hay que considerar que estas propiedades inhibidoras van a variar en respuesta a las condiciones físico químicas del medio y/o biológica, ya sea, por el tipo de especie que interactúe y la especies objetivo que se quiera atacar. Mieszkin et al., (2013) proponen como una alternativa viable el uso de productos obtenidos de las interacciones bacterias y microalgas para controlar la macro bioincrustación. Igualmente Simon et al., (2013) proponen el uso de un biofiltro de microbios para la prevención de contaminantes biológicos en instalaciones de tratamiento de agua, inmovilizando los productos bioactivos bacterianos en pinturas. Por ejemplo Burgess et al., (2003) probaron una pintura con extractos de Pseudomonas sp. NUDMB50-11, demostrando una buena actividad inhibidora del asentamiento de larvas de lapa Balanus amphitrite e inhibición del crecimiento de Ulva lactuca. Igualmente, Rajan et al., (2016) observaron buenos resultados al implementar la incorporación de extractos activos de Gracilaria edulis en pinturas, para evaluar las propiedades anti-corrosivas y anti-incrustantes contra bacterias patógenas.

La bacteria Alteromonas sp. Ni1-LEM usada como control positivo en este trabajo, fue previamente aislada desde la bahía san Jorge de Antofagasta y patentada sus propiedades anti bioincrustantes por Riquelme et al., (2008). Existen registros que confirman sus productos de naturaleza peptídica como inhibidores del asentamiento de invertebrados marinos bentónicos y planctónicos (Ayala et al., 2006; Zapata et al., 2007) así como la adherencia de diatomeas de los géneros Nitzschia y Amphora (SilvaAciares y Riquelme, 2008) que constituyen especies representativas de bioincrustantes primarios. Nuestros resultados reflejaron que esta bacteria presentó mejor actividad inhibidora respecto a los tratamientos de M9-5 y $\mathrm{C} 32$ en ambas experiencias. Estos resultados nuevamente reafirman las propiedades inhibidoras de la bacteria Alteromonas sp. Ni1-LEM.

Las bacterias B. pumilus M9-5-MESO y C32-MESO presentaron inhibición significativa en la fijación de las diferentes mezclas microalgales en sustratos, respecto a los controles sin bacterias. Sin embargo la mejor actividad se observó en $B$. pumilus M9-5-MESO. Nuevamente se reafirma la potencialidad antibacteriana reportada para B. pumilus C32-MESO por Leyton et al., (2012). Igualmente, Ismail et al., (2016) atribuyen propiedades inhibidoras contra una variedad de bacterias patógenas de la especie $B$. pumilus aislada desde el alga Padina pavonica. Otros estudios, han demostrado que $B$. pumilus inhibe bacterias y hongos como Mucoraceae y Aspergillus (Botton y Peluso, 2003). Por otra parte, Jin et al., (2014) evaluaron actividad inhibidora de B. pumilus, aislado desde esponjas marinas, contra la diatomea Stauroneis sp. Zhang et al., (2013) comprobaron que la bacteria B. pumilus SW9 disminuyó el crecimiento 
de otras bacterias formadoras de bioincrustantes en membranas de microfiltración. Respecto al género Bacillus Korenblum et al., (2012) indicó que producen sustancias que inhiben bacterias reductoras de sulfato responsables de la biocorrosión en la industria petrolera. Otra especie de este género como Bacillus lincheniformis han demostrado potencialidad antiincrustantes y anticorrosivas, estas propiedades se pueden atribuir a que las endosporas mejoran la hidrofobicidad alterando la humedad de la superficie e impidiendo la difusión de moléculas/iones de la corrosión a través del revestimiento de la superficie de metal, como también a la acción como antibiótico de las esporas después de la encapsulación bacteriana (Eduok et al., 2015).

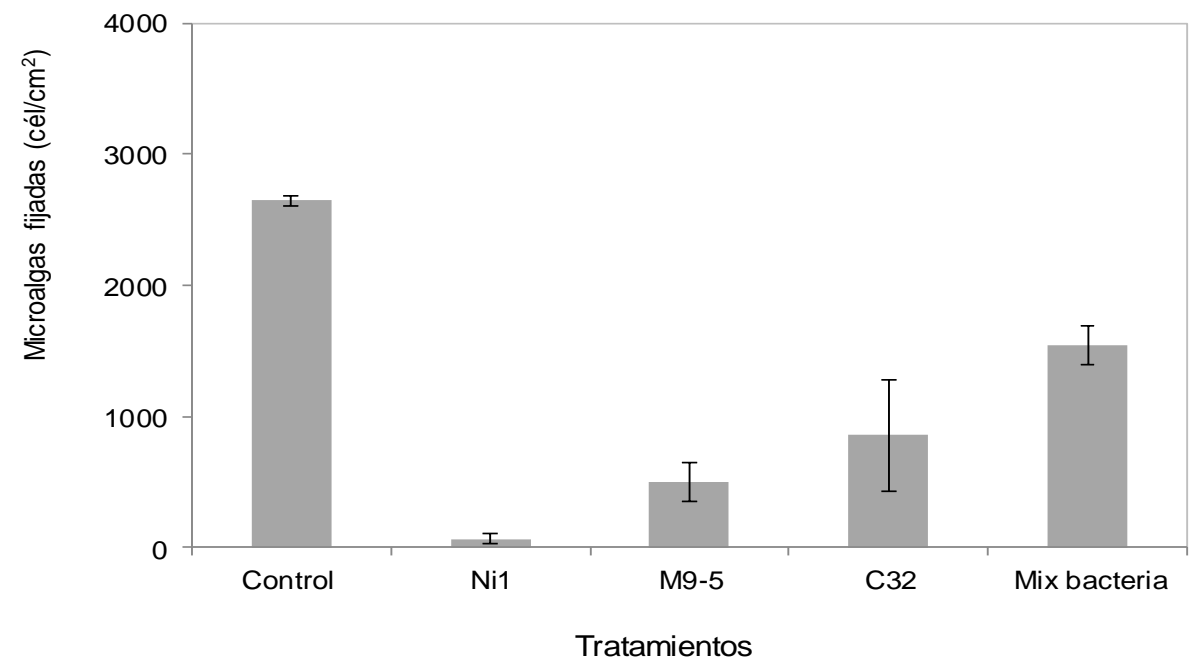

Fig. 2: Adherencia del Mix AC14/AC16 a sustratos biologizados con bacterias. Control: Mix AC14/AC16; Ni1: bacteria Ni1-LEM+Mix AC14/AC16; M9-5: bacteria M9-5-MESO+Mix AC14/AC16; C32: bacteria C32MESO+Mix AC14/AC16; Mix bacteria: bacteria Ni1-LEM+M9-5-MESO+C32-MESO+Mix AC14/AC16.

La mezcla de bacteria presentó una significativa inhibición de la fijación a los sustratos del Mix UA, incluso la actividad se potenció aún más que cuando se evaluó la fijación de las bacterias por separado. Por el contrario a lo ocurrido con el Mix AC14/AC16 donde el Mix bacteriano no causó el mismo efecto inhibitorio, sino que las bacterias por separado presentaron mejor actividad. Este comportamiento se puede explicar porque al mezclar más de una especie bacteriana en el medio se va a generar naturalmente una competencia por sustrato. Si bien las tres especies bacterianas se inocularon en igual concentración, por selección natural siempre una bacteria va a tener diferentes comportamientos que la otra, y va a estar directamente relacionado el tipo de especie con quien este compitiendo. De esta interacción va a depender los componentes de los exopolisacaridos que se cementaran en las biopelículas y por consecuencia va a influir en la señal de inducción para las microalgas que se van a fijar al sustrato. Hay que considerar que cada mezcla de microalgas (UA y AC14/AC16) está compuesto por distintas especies que explicaría la diferencia en el comportamiento de fijación. Comentarios similares son discutidos por Lam et al., (2003) quienes indican que las señales de asentamiento a los sustratos en los macroorganismos estarían influenciadas por los polisacáridos secretados por las microalgas.

Los resultados de esta investigación confirman la actividad inhibidora de bacterias marinas $B$. pumilus, contra la formación de bioincrustantes microalgales en sustratos. En base a estos resultados hicimos una revisión bibliográfica para buscar trabajamos similares al nuestro. Encontramos un trabajo publicado por Xin et al (2016) quienes aislaron un B. pumilus desde una esponja marina, la cual demostró actividad anti microalgas (diatomeas), los compuestos bioactivos de esta bacteria fueron aislados por técnicas cromatograficas, purificados por cromatografía liquida (HPLC) y las estructuras moleculares fueron identificados por espectroscopia de resonancia magnética nuclear, espectrometría de masas y cromatografía de gases. Los resultados demostraron por primera vez que los ácidos grasos de $B$. pumilus inhiben la adhesión de diatomeas a sustratos. Estos antecedentes nos indican que debemos aprovechar las potencialidades anti bioincrustantes naturales que nos brinda la naturaleza como las de B. pumilus y complementarlas con los avances científicos que existen en la actualidad como los mencionados y discutidos por Kahlon, (2016) referentes a genómica, proteómica, transcriptómica y metabolómica que permiten predecir el potencial metabólico de una especie de interés. Así como sintetizar los productos activos para usarlos en ambientes afectados por contaminantes orgánicos como fenoles policlorados, bifenilos, hidrocarburos aromáticos policíclicos, hidrocarburos de petróleo, pesticidas y contaminantes biológicos como micro y macroorganismos. 


\section{CONCLUSIONES}

Basado en los resultados obtenidos es posible concluir que desde la Bahía de Antofagasta se aisló la bacteria Bacillus pumilus, especie común de encontrar en las comunidades marinas por su capacidad de adaptación. Además los resultados demostraron que es viable utilizar bacterias marinas como B. pumilus para inhibir la fijación inicial a sustratos artificiales como PVC, de microalgas nativas de las costas del norte de Chile. En base a estas conclusiones se debieran seguir desarrollando investigaciones que permitan identificar los metabolitos inhibitorios y mediante nuevas herramientas moleculares producirlos in vitro e inmovilizarlos en sustratos artificiales para prevenir el desarrollo de bioincrustaciones.

\section{AGRADECIMIENTOS}

Los autores agradecen al financiamiento de CONICYT (Anillo ACT 1201), al Gobierno Regional de Antofagasta, FIC-Región de Antofagasta (Chile). Además, agradecen al proyecto FONDEF ID1410072.

\section{REFERENCIAS}

Al-Aarajy, M.J. Some observation on an accident fish mortality in northwest Arabian Gulf. Marina Mesopotamica: 16 (2), $431-439$ (2001)

Almeida, J.R. y Vasconcelos, V. Natural antifouling compounds: Effectiveness in preventing invertebrate settlement and adhesión. Biotechnology Advances: 33, 343 - 357 (2015)

Ayala, C., Clarke, M. y Riquelme, C. Inhibition of byssal formation in Semimytilus algosus (Gould, 1850) by a film-forming bacterium isolated from biofouled substrata in northern Chile. Biofouling: 22: $61-68$ (2006)

Bottone, E.J. y Peluso, R.W. Production by Bacillus pumilus (MSH) of an antifungal compound that is active against Mucoraceae and Aspergillus species: preliminary report. Department of Medicine, Division of Infectious Diseases. Journal of Medical Microbiology: 52, 69 -74 (2003)

Bruder, K. Taxonomic Revision of Diatoms belonging to the family Naviculaceae based on morphological and molecular data (Doctoral dissertation, Universität Bremen) (2006)

Burgess, J.G. y otros 9 autores. The Development of a Marine Natural Product-based Antifouling Paint. Biofouling: 19,197-205 (2003)

Cefarelli, A.O, Ferrario, M.E. y Vernet, M. Diatoms (Bacillariophyceae) associated with free-drifting Antarctic icebergs: taxonomy and distribution. Polar Biology: 39,443 - 459 (2016)

Dobretsov, S. y otros 7 autores. Inhibition of bacterial fouling by soft coral natural products. International Biodeterioration \& Biodegradation: 98, 53 - 58 (2015)

Eduok, U. y otros 7 autores. Anticorrosion/antifouling properties of bacterial spore-loaded sol-gel type coating for mild steel in saline marine condition: a case of thermophilic strain of Bacillus licheniformis. Royal Society of chemistry advances: $5,93818-93830$ (2015)

Ferrario, M.E. y Ferreyra, G.A. Diatoms of the South Orkney Islands. Biomass Science Serie: 7, $39-52$ (1987)

Fuentes, J. y otros 5 autores. Impact of Microalgae-Bacteria Interactions on the Production of Algal Biomass and Associated Compounds. Marine drugs: 14(5), 100 (2016)

Guillard, R.R.L. y Ryther, J.H. Studies of marine planktonic diatoms. I. Cyclotella nana Hustedt and Detonula confervacea Cleve. Canadian Journal of Microbiology: 8, 229 - 239 (1962)

Hsin-Pei, T., Lu-Te C. y Ching-Nen, N.C. Production of long chain omega-3 fatty acids and carotenoids in tropical areas by a new heat-tolerant microalga Tetraselmis sp. DS3. Food Chemistry: 192, $682-690$ (2016)

Jhaveri, J.H. y Murthy Z.V.P. A comprehensive review on anti-fouling nanocomposite membranes for pressure driven membrane separation processes. Desalination: 379, 137-154 (2016)

Ismail, A. y otros 7 autores. Antimicrobial Activities of Bacteria Associated with the Brown Alga Padina pavonica. Frontiers in Microbiology: 7, 1072 (2016) 
lyapparaj, P. y otros 6 autores. Antifouling activity of the methanolic extract of Syringodium isoetifolium, and its toxicity relative to tributyltin on the ovarian development of brown mussel Perna indica. Ecotoxicology and Environmental Safety: 89, $231-238$ (2013)

Ivorra, N. y otros 5 autores. Translocation of microbenthic algal assemblages used for in situ analysis of metal pollution in rivers. Archives of Environmental Contamination and Toxicology: 37(1), $19-28$ (1999)

Jin, C. y otros 6 autores. Antidiatom activity of marine bacteria associated with sponges from San Juan Island, Washington. World Journal of Microbiology and Biotechnology: 30(4), 1325 - 1334 (2014)

Kahlon, R.S. Biodegradation and Bioremediation of Organic Chemical Pollutants by Pseudomonas. Book Title Pseudomonas: Molecular and Applied Biology. Springer International Publishing Switzerland: pp 343 417 (2016)

Khan, S.A.M. y Jintae, L. Novel Strategies for Combating Pathogenic Biofilms Using Plant Products and Microbial Antibiosis. Current Pharmaceutical Biotechnology, Publisher: Bentham Science Publishers, 17(2), $126-140(2016)$

Kochkodan, V.M. y Sharma, V.K. Graft polymerization and plasma treatment of polymer membranes for fouling reduction: a review. Journal of Environmental Science and Health, Part A: 47, 1713-27 (2012)

Korenblum, E. y otros 10 autores. Purification and characterization of a surfactin-like molecule produced by Bacillus sp. $\mathrm{H}_{2} \mathrm{O}-1$ and its antagonistic effect against sulfate reducing bacteria. BMC Microbiology: 12, 252 (2012)

Lam, C., Harder, T. y Qjan, P.Y. Induction of larval settlement in the polychaete Hydroides elegans by surface associated settlement cues of marine benthic diatoms. Marine Ecology Progress Series: 263, 83-92 (2003)

Levkov, Z. y Williams, D.M. Fifteen new diatom (Bacillariophyta) species from Lake Ohrid, Macedonia. Phytotaxa: 30, $1-41$ (2011)

Leyton, Y. y otros 5 autores. Diketopiperazines produced by an marine Bacillus species inhibits Vibrio parahaemolyticus. Aquaculture Research and Development: 3,144 (2012)

Liming, L, Rongbin, D.U. y Xiaoling, Z. Succession and seasonal variation in epilithic biofi Ims on artifi cial reefs in culture waters of the sea cucumber Apostichopus japonicas. Chinese Journal of Oceanology and Limnology. http://dx.doi.org/10.1007/s00343-016-5205-z. (2016)

Majewska, R., Zgrundo, A., Lemke, P. y De Stefano M. Benthic diatoms of the Vistula River estuary (Northern Poland): Seasonality, substrata preferences, and the influence of water chemistry. Phycological Research: 60, 1-19 (2012)

Mejdandžić, M. y otros 6 autores. Colonization of diatoms and bacteria on artificial substrates in the northeastern coastal Adriatic Sea. Acta Botanica Croatica: 74(2), 407 - 422 (2015)

Mieszkin, S., Callow, M.E. y Callow, J.A. Interactions between microbial biofilms and marine fouling algae: a mini review. Biofouling: 29(9), 1097-1113 (2013)

NCBI. National Center for Biotechnology Information, U.S. National Library of Medicine. En la web: ncbi.nlm.nih.gov/blast/Blast.cgi (2016)

Ortigosa, M., Garay, E. y Pujalte, M-J. Gram-positive bacteria of marine origin: a numerical taxonomic study on Mediterranean isolates. Microbiologia: 13 (4), 453 - 462 (1997)

Petroutsos, D., Katapodis, P., Samiotaki, M., Panayotou, G. y Kekos, D. Detoxification of 2, 4-dichlorophenol by the marine microalga Tetraselmis marina. Phytochemistry: 69(3), $707-714$ (2008)

Qian, P.Y, Li, Z., Xu, Y y Li, Y., Fusetani, N. Mini-review: Marine natural products and their synthetic analogs as antifouling compounds: 2009-2014. Biofouling: The Journal of Bioadhesion and Biofilm Research 31(1), $101-22(2015)$ 
Qureshi, A., Smita, P., Saheli G., Atya K. y Purohit H.J. Antibiofouling biomaterials. International Journal of Recent Advances in Multidisciplinary Research: 2(8), 0677-0684 (2015)

Rabin, N. y otros 5 autores. Agents that inhibit bacterial biofilm Formation. Future Medicinal Chemistry. 7(5), $647-671(2015)$

Rajan, R., Selvaraj, M., Palraj, S. y Subramanian, G. Studies on the anticorrosive \& antifouling properties of the Gracilariaedulis extract incorporated epoxy paint in the Gulf of Mannar Coast,Mandapam, India. Progress in Organic Coatings: 90, $448-454$ (2016)

Riquelme, C., Silva-Aciares, F., Clarke, M. Bacterial Product From Marine Origin, Useful For Preventing The Macro Biofouling Caused By Macroalgae And Marine Invertebrates. Document Type and Number: United States Patent 20080095871 Kind Code: A1. Application Number: 11/577248. Publication Date: 04/24/2008 (2008)

Robinson, N.J. y otros 7 autores. Epibiotic Diatoms Are Universally Present on All Sea Turtle Species. PloS one, 11(6), e0157011 (2016)

Round, F.E., Crawford, R.M. y Mann, D.G. The diatoms, biology \& morphology of the genera. Cambridge University Press, Cambridge. 747 páginas (1990)

Silva-Aciares, F. y Riquelme, C. Inhibition of attachment of some fouling diatoms and settlement of Ulva lactuca zoospores by film-forming bacterium and their extracellular products isolated from biofouled substrata in Northern Chile. Electronic Journal Biotechnology, 11(1) (2008)

Suresh, M., Iyapparaj, P. y Anantharaman, P. Antifouling Activity of Lipidic Metabolites Derived from Padina tetrastromatica. Applied biochemistry and biotechnology: 1-14 (2016)

Susilowati, R., Sabdono, A., y Widowati, I. Isolation and characterization of bacteria associated with brown algae Sargassum spp. from Panjang Island and their antibacterial activities. Procedia Environmental Science $23,240-6(2015)$

Tan, T.H. y otros 6 autores. Marine micro-phytoplankton of Singapore, with a review of harmful microalgae in the region. Raffles Bulletin Of Zoology Supplement: 34, 78 - 96 (2016)

Xin, X., Huang, G., Zhou, X., Sun, W., Jin, C., Jiang, W., y Zhao, S. Potential antifouling compounds with antidiatom adhesion activities from the sponge-associated bacteria, Bacillus pumilus. Journal of Adhesion Science and Technology: 1-16 (2016)

Yang, C., Sun W., Liu S. y Xia, C. Comparative effects of indole derivatives as antifouling agents on the growth of two marine diatom species. Chemistry and Ecology: 31(4), 299 - 307 (2015)

Zhang, Y. y otros 6 autores. Heavy metals in aquatic organisms of different trophic levels and their potential human health risk in Bohai Bay, China. Environmental Science and Pollution Research. DOI 10.1007/s11356-016-6948-y (2016)

Zhang, Y. y otros 5 autores. Antibiofilm activity of Bacillus pumilus SW9 against initial biofouling on microfiltration membranes. Applied Microbiology and Biotechnology: 98(3), 1309 - 1320 (2013)

Zapata, M., Silva, F., Luza, Y., Wilkens, M. y Riquelme, C. The inhibitory effect of biofilms produced by wild bacterial isolates to the larval settlement of the fouling ascidia Ciona instestinalis and Pyura praeputialis. Electronic Journal of Biotechnology: 10(1), 149 (2007)

Zhipeng, Z. y otros 6 autores. Seasonal variations in the phytoplankton community and the relationship between environmental factors of the sea around Xiaoheishan Island in China. Chinese Journal of Oceanology and Limnology. http://dx.doi.org/10.1007/s00343-016-5241-8 (2016) 